\title{
PENGARUH UKURAN BUTIRAN MAKSIMUM TERHADAP KUAT TEKAN REACTIVE POWDER CONCRETE
}

\author{
Arianti Sutandi ${ }^{1}$, Widodo Kushartomo ${ }^{2}$ \\ ${ }^{1}$ Jurusan Teknik Sipil, Universitas Tarumanagara Jakarta \\ Email: ariantis@ft.untar.ac.id \\ ${ }^{2}$ Jurusan Teknik Sipil, Universitas Tarumanagara jakarta \\ Email:widodo@untar.ac.id
}

Masuk: 30-085-2019, revisi: 01-09-2019, diterima untuk diterbitkan: 02-09-2019

\begin{abstract}
ABSTRAK
Kuat tekan beton merupakan faktor yang paling dominan untuk menentukan kualitas beton dibandingkan faktor lainnya. Kuat tekan beton atau mutu beton dipengaruhi oleh beberapa faktor diantaranya adalah perbandingan semen terhadap air $\left(\mathrm{f}_{\mathrm{a} / \mathrm{s}}\right)$, kualitas material, perbandingan komposisi material dan sebagainya. Gradasi butiran agregat juga merupakan salah satu faktor yang berperan penting untuk menentukan mutu beton. Agregat dengan ukuran butiran yang lebih halus dan bervariasi dapat memperkecil volume pori yang terbentuk, sehingga susunan butiran yang baik akan menghasilkan kepadatan tinggi dan porositas minimum. Pada penelitian ini dipelajarai pengaruh ukuran butiran maksimum agregat halus terhadap kuat tekan reactive powder concrete. Benda uji dibuat dalam bentuk silinder dengan diameter 100,0 $\mathrm{mm}$ dan tinggi $200,0 \mathrm{~mm}$. Ukuran diameter maksimum agergat halus dibuat dalam tiga jenis yaitu $300 \mu \mathrm{m} .425 \mu \mathrm{m}$, dan $600 \mu \mathrm{m}$. Seluruh benda uji dirawat dengan teknik perendaman selama 3 hari, dilanjutkan dengan steam curing pada temperature $90{ }^{\circ} \mathrm{C}-95{ }^{\circ} \mathrm{C}$ selama 4 jam. Pengujian kuat tekan dilakukan pada umur 7 hari. Hasil pengujian menunjukkan terjadinya peningkatan kuat tekan recative powder concrete dengan bertambah kecilnya ukuran butiran maksimum agregat halus.
\end{abstract}

Kata Kunci: agregat; maksimum; beton; kuat; tekan

\begin{abstract}
The compressive strength of concrete is the most dominant factor to determine concrete quality compared to other factors. Concrete compressive strength and grade are influenced by several factors, including water cement ratio $\left(f_{a / s}\right)$, material quality, material composition, and others. Aggregate gradation is also one of the dominant factors that play an important role in determining the quality of concrete. Finer and varied aggregate size can reduce void volume, so that a good granular structure will produce high density and minimum porosity. In this research, the effect of maximum size of fine aggregate on the compressive strength of reactive powder concrete was studied. The specimens were made in cylindrical shapes with a diameter of $100.0 \mathrm{~mm}$ and a height of $200.0 \mathrm{~mm}$. The maximum diameter size of fine agergate was varied in three types, $300 \mu \mathrm{m} .425 \mu \mathrm{m}$, and $600 \mu \mathrm{m}$. All specimens were treated with immersion technique for 3 days, followed by steam curing at $90^{\circ} \mathrm{C}-95^{\circ} \mathrm{C}$ for 4 hours. Compressive strength testing was done at the age of 7 days. The test results showed that the increase of maximum fine aggregate size increase the compressive strength of reactive powder concrete.
\end{abstract}

Keywords: aggregate; maximum; concrete; compressive strength

\section{PENDAHULUAN \\ Latar Belakang}

Beton merupakan material yang sangat diperlukan dalam bidang industri konstruksi, pada umumnya beton tersusun atas pasta semen dan agregat. Beton merupakan material heterogen dengan kekuatan tekan terbatas dan kekuatan tarik sangat rendah, sehingga dalam aplikasi struktur ditambahkan besi penulangan di dalam beton untuk meningkatkan kekuatan tarik. Perkembangan terkini dalam teknologi beton adalah reactive powder concrete (RPC), RPC 
menjadi sebuah pilihan yang dapat digunakan untuk menggantikan beton biasa dalam segala hal penggunaan di bidang konstruksi.

RPC merupakan material beton komposit yang memiliki kekuatan dan keuletan tinggi serta porositas rendah (Graybeal, 2007). RPC tersusun atas semen, air, silica fume, tepung kuarsa, pasir kuarsa dan serat baja. Selain komposisi material dan kualitas material penyusun, faktor utama yang menunjang kekuatan RPC adalah volume pori-pori. Pada kebanyakan material getas, kekuatan dan porosistas dapat dikorelasikan sebagai sebuah persamaan (Mindess \& Young, 1981)

$$
\mathrm{S}=\mathrm{S}_{0} \mathrm{e}^{-\mathrm{kP}}
$$

dengan: $\mathrm{S}=$ kekuatan, $\mathrm{S}_{0}=$ kekuatan pada pori-pori $0, \mathrm{k}=$ konstanta dan $\mathrm{P}=$ volume pori-pori.

Dari persamaan-1 dapat dilihat bahwa jika volume pori-pori semakin besar maka kekuatan material beton akan semakin rendah. Dengan mengeliminasi agregat kasar dan membuat komponen penyusun beton berupa tepung, maka RPC dapat tersusun secara kompak dan homogen, jauh lebih baik bila dibandingkan dengan beton biasa maupun dengan beton berkinerja tinggi (High Performance Concrete).

Gradasi yang baik adalah gradasi yang menerus dimana seluruh ukuran butiran terdapat dalam agregat tersebut sehingga menciptakan butiran yang heterogen. Butiran yang heterogen akan mampu untuk menempatkan posisi untuk saling mengisi rongga-rongga yang kosong sesuai dengan ukurannya.

Susunan butiran yang baik dapat menghasilkan kepadatan tinggi dan porositas minimum. Butiran yang lebih kecil akan mengisi pori antara butiran yang lebih besar, sehingga pori-porinya menjadi sedikit dan beton memiliki kepadatan yang tinggi.

Teknologi ukuran agregat super kecil (skala nanometer) membuka jalan untuk melakukan optimasi untuk mendapatkan susunan material pada suatu volume tertentu yang ultra padat atau disebut sebagai packing density (Purwanti dkk, 2014). Kepadatan yang sangat tinggi diperoleh karena ruang-ruang kosong diantara partikel-partikel diisi butiran debu halus berukuran nanometer seperti mikrosilika ataupun partikel mineral lainnya. Beton kinerja tinggi dibuat dengan susunan struktur beton yang sangat padat, dimana pori-pori yang terbentuk berada dalam ukuran $2 \mathrm{~nm}$, lebih kecil dari ukuran kapiler atau praktis tidak mengandung lagi pori-pori berukuran kapiler. Akibat sedikitnya pori-pori yang ada pada suatu volume tertentu dari beton kinerja tinggi, maka pada campuran beton kinerja tinggi jumlah air dapat dikurangi sampai mencapai kurang lebih $20 \%$ dari berat semen.

\section{Rumusan Masalah}

Reactive powder concrete (RPC) merupakan beton dengan kinerja tinggi baik dari segi mekanis maupun fisis yang tersusun atas semen, air, silica fume, tepung marmer, pasir dan superplasticizer. Untuk meningkatkan kinerja RPC dapat dilakukan dengan menggunakan densified mixture design algoritm (DMDA). DMDA merupakan metode perencanaan campuran beton yang mengutamakan kepadatan (Puoch dan Lung, 2018). Metode ini memanfaatkan material penyusun beton dengan ukuran butiran sangat halus seperti silica fume, abu terbang, tepung marmer dan agregat halus sehingga diperoleh beton dengan tingkat kepadatan yang tinggi. Dengan memperhatikan uraian tersebut diatas perlu dilakukan pengkajian terhadap pengaruh ukuran butiran maksimum pasir terhadap kuat tekan reactive powder concrete. Apakah ukuran butiran maksimum pasir mempengaruhi nilai kuat tekan RPC? 


\section{METODE PENELITIAN}

Untuk dapat mencapai tujuan, dan menjawab semua pertanyaan pada penelitian yang akan dikerjakan ini, metode penelitian yang digunakan dalam pengumpulan data adalah penelitian eksperimental dimana sejumlah pengujian, perawatan dan metode karakterisasi dikerjakan untuk menentukan pengaruh ukuran butiran maksimal terhadap nilai kuat tekan RPC dengan langkahlangkah penelitian sebagai berikut. Langkah pertama yang dilakukan dalam pelaksanaan penelitian ini adalah properties material. Pemeriksaan properties dilakukan terhadap agregat halus atau pasir yang meliputi berat isi, kadar organis, kadar lumpur, gradasi butiran, dan berat jenis serta penyerapannya. Pemeriksaan dilanjutkan dengan pemilihan ukuran butiran maksimumnya mulai dari $600 \mu \mathrm{m}, 425 \mu \mathrm{m}$ dan $300 \mu \mathrm{m}$. Langkah selanjutnya yang dilakukan adalah menyiapkan rencana campuran berdasarkan volume dengan rencana seperti disajikan pada persamaan-2 berikut:

$$
\mathrm{V}_{\mathrm{a}}+\mathrm{V}_{\mathrm{s}}+\mathrm{V}_{\mathrm{sf}}+\mathrm{V}_{\mathrm{m}}+\mathrm{V}_{\mathrm{p}}+\mathrm{V}_{\mathrm{sp}}=1
$$

Keterangan:

$\mathrm{V}=$ volume $; \mathrm{a}=$ air $; \mathrm{s}=$ semen $; \mathrm{sf}=$ silica fume $; \mathrm{m}=$ tepung marmer $; \mathrm{p}=$ pasir; $\mathrm{sp}=$ super plasticizer

Tabel 1 Perancangan campuran contoh uji RPC

\begin{tabular}{cccccccccc}
\hline Material & C1-1 & C1-2 & C1-3 & C2-1 & C2-2 & C2-3 & C3-1 & C3-2 & C3-3 \\
\hline Semen & 1.00 & 1.00 & 1.00 & 1.00 & 1.00 & 1.00 & 1.00 & 1.00 & 1.00 \\
\hline Air & 0.22 & 0.22 & 0.22 & 0.20 & 0.20 & 0.20 & 0.18 & 0.18 & 0.18 \\
\hline Slica fume & 0.30 & 0.30 & 0.30 & 0.30 & 0.30 & 0.30 & 0.30 & 0.30 & 0.30 \\
\hline Tepung Marmer & 0.30 & 0.30 & 0.30 & 0.30 & 0.30 & 0.30 & 0.30 & 0.30 & 0.30 \\
\hline Pasir & 1.50 & 1.50 & 1.50 & 1.50 & 1.50 & 1.50 & 1.50 & 1.50 & 1.50 \\
\hline Super Plasticizer & 0.03 & 0.03 & 0.03 & 0.03 & 0.03 & 0.03 & 0.03 & 0.03 & 0.03 \\
\hline Diameter Pasir $(\mu \mathrm{m})$ & 300 & 425 & 600 & 300 & 425 & 600 & 300 & 425 & 600 \\
\hline
\end{tabular}

Benda uji dibuat dalam bentuk silinder yang beriameter $\varnothing 100.0 \mathrm{~mm}$, tinggi $200.0 \mathrm{~mm}$, masingmasing sebanyak 5 benda uji untuk setiap kode campuran. Perawatan benda uji dilakukan dengan teknik perendaman selama 3 hari yang dilanjutkan dengan teknik penguapan (steam curing) pada temperature $90^{\circ} \mathrm{C}-95^{\circ} \mathrm{C}$ selama 4 jam. Seluruh benda uji di tes pada umur 7 hari ditujukan untuk mencari nilai kuat tekan RPC akibat pengaruh ukuran butiran maksimum agregat halus.

\section{HASIL DAN PEMBAHASAN}

\section{Data}

Berdasarkan pengujian yang telah dilakukan terhadap seluruh benda uji, diperoleh data-data pengujian seperti yang disajikan pada tabel 3.1 berikut. 
Tabel 2. Pengujian kuat tekan benda uji

\begin{tabular}{crcc}
\hline \multirow{2}{*}{ Kode } & \multicolumn{3}{c}{ Nilai Kuat tekan } \\
& \multicolumn{3}{c}{$\mathrm{N} / \mathrm{mm}^{2}$} \\
\hline & $300 \mu \mathrm{m}$ & $425 \mu \mathrm{m}$ & $600 \mu \mathrm{m}$ \\
\hline 0,20 & 141 & 133 & 121 \\
\hline 0,22 & 136 & 115 & 110 \\
\hline 0,25 & 123 & 107 & 102 \\
\hline
\end{tabular}

\section{Analisis}

Kuat tekan merupakan ukuran kemampuan beton menahan gaya yang bekerja tegak lurus bidang tekan. Hubungan besaran-besaran tersebut ditunjukkan seperti pada persamaan-3

$$
f_{c}^{v}=\frac{P}{A}
$$

dengan :

$$
\begin{array}{ll}
f_{e}^{y} & =\text { tegangan tekan beton, } \mathrm{MPa} \\
\mathrm{P} & =\text { besar beban tekan, } \mathrm{N} \\
\mathrm{A} & =\text { luas penampang beton, } \mathrm{mm}^{2}
\end{array}
$$

Kuat tekan beton merupakan sifat terpenting dalam kualitas beton dibanding dengan sifat-sifat lain (Hong dkk, 2016), (Hou dkk, 2017). Kekuatan tekan beton ditentukan oleh pengaturan dari perbandingan semen terhadap air $(\mathrm{Fa} / \mathrm{s})$ juga komposisi agregat. Gradasi agregat juga memegang peranan penting untuk menentukan mutu beton. Apabila agregat mempunyai ukuran butiran yang lebih halus dan dengan ukuran yang bervariasi, maka volume pori beton menjadi kecil. Susunan butiran yang baik dapat menghasilkan kepadatan tinggi dan porositas minimum. Butiran yang lebih kecil akan mengisi pori antara butiran yang lebih besar, sehingga pori-porinya menjadi sedikit dan beton memiliki kepadatan yang tinggi. Seperti disajikan pada persamaan-1 jelas memperlihatkan, semakin besar volume pori-pori terbentuk maka nilai kuat tekan beton akan semakin menurun.

Gambar 3.1 menunjukkan pengaruh ukuran butiran maksimum terhadap kuat tekan beton. Gambar tersebut mengatakan bahwa semakin besar ukuran butiran maksimum agregat halus, semakin kecil nilai kuat tekan beton. Demikian juga semakin besar nilai perbandingan air terhadap semen nilai kuat tekan beton semakin kecil. Ini bisa dijelaskan sebagai berikut:

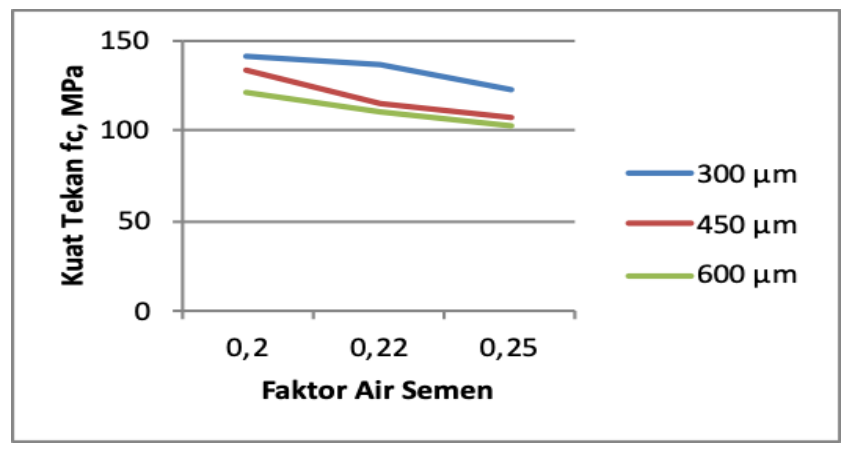

Gambar 1. Pengaruh ukuran butiran dan faktor air semen terhadap nilai kuat tekan reactive powder concrete 
Densified Mixture Design Algoritm (DMDA) merupakan metode perencanaan campuran beton yang dikembangkan oleh National Taiwan University of Science and Technology. DMDA adalah perencanaan campuran beton yang mengutamakan kepadatan (Puoch dan Lung, 2018). Metode ini memanfaatkan material penyusun beton dengan ukuran butiran sangat halus seperti silica fume, abu terbang dan agregat halus sehingga diperoleh beton dengan tingkat kepadatan yang tinggi.

Terdapat dua parameter yang harus diperhatikan dalam merencanakan beton menggunakan metode DMDA yaitu parameter alfa $(\alpha)$ dan parameter beta $(\beta)$ (Chang, 2004). Parameter alfa merupakan perbandingan antara silica fume dengan tepung marmer, kemudian campuran silica fume dengan tepung marmer yang berkepadatan tinggi dicampur dengan agregat halus sesuai dengan ukuran butiran yang digunakan.

$$
\begin{aligned}
& \alpha=\frac{\mathrm{w}_{\mathrm{m}}}{\mathrm{w}_{\mathrm{m}}+\mathrm{w}_{\mathrm{sf}}} \times 100 \% \\
& \beta=\frac{\left(\mathrm{w}_{\mathrm{m}}+\mathrm{w}_{\mathrm{sf}}\right)}{\left(\mathrm{w}_{\mathrm{m}}+\mathrm{w}_{\mathrm{sf}}\right)+\mathrm{w}_{\mathrm{p}}} \times 100 \%
\end{aligned}
$$

Volume rongga antar butiran yang terbentuk dihitung dengan:

$$
V_{v}=1-\sum \frac{w_{i}}{\rho_{i}}
$$

Dengan: $\mathrm{W}=$ massa.....kg

$$
\rho=\text { massa jenis..... } \mathrm{kg} / \mathrm{m}^{3}
$$

Jumlah volume rongga atau pori-pori yang terbentuk berkaitan dengan kekuatan pada reactive powder concrete. Semakin banyak volume pori-pori yang terbentuk maka nilai kuat tekan RPC juga semakin menurun (Mindess dan Young, 1981). Persamaan-4, persamaan-5 dan persaman-6 menjelaskan tingkat kepadatan RPC terkait dengan ukuran butiran maksimum. Semakin besar ukuran butiran maksimum agregat halus $(600 \mu \mathrm{m})$ maka volume pori-pori yang terbentuk semakin besar dan ini merakibat nilai kekuatan RPC dalam hal ini kuat tekannnya juga akan mengalami penurunan. Penjelasan ini sesuai pada Gambar 3.1. yang memperlihatkan bila ukuran butiran semakin besar maka nilai kuat tekannya juga semakin kecil.

Apabila diperhatikan nilai perbandingan Faktor air semen $\left(\mathrm{F}_{\mathrm{a} / \mathrm{s}}\right)$, Gambar 3.1. menunjukkan nilai kuat tekan tekan RPC semakin menurun apabila perbandingan nilai faktor air semen RPC semakin membesar. Hal ini bisa dijelaskan sebagai berikut:

Ukuran butiran agregat yang lebih besar cenderung memiliki gesekan yang lebih kecil bila dibandingkan dengan ukuran butiran yang kecil, ini disebabkan butiran yang besar memiliki luas permukaan jauh lebih kecil bila dibandingkan dengan butiran yang halus, sehingga dengan komposisi bahan yang sama kebutuhan air menjadi berlebih banyak dan membuat adukan lebih encer (Ahmad, 2015). Bila jumlah air yang digunakan lebih banyak akan membentuk pori-pori yang lebih banyak juga sehingga kuat tekan beton menjadi menurun. 
Pada proses hidrasi semen yaitu bereaksinya antara air dan semen akan menghasilkan gel C-S-H yang berfungsi sebagai bahan pengikat, pori-pori gel dan pori-pori kapiler (Neville, 2012). Reaksi hidrasi yang terjadi menurut Mindess dan Young (1981) dituliskan sebagai berikut:

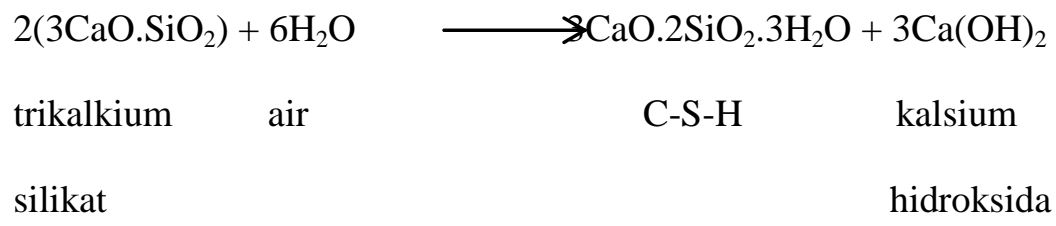

Volume C-S-H yang terbentuk dipengaruhi oleh nilai perbandingan jumlah air dan semen $\left(\mathrm{F}_{\mathrm{a} / \mathrm{s}}\right)$ dan temperature perawatan (Heremath \& Yaragal, 2017), (Hou dkk, 2017), (JU dkk, 2017), (Kamen, 2017). Gambar 3.2 memberikan gambaran volume produk hidrasi yang terbentuk dikaitkan dengan faktor air semen. Semakin besar nilai faktor air semen maka volume pori-pori yang terbentuk juga semakin banyak. Hal ini lah yang menyebabkan mengapa terjadi penurunan nilai kuat tekan RPC pada Gambar 4.1. terhadap kenaikan nilai faktor air semen. Artinya bila faktor air semen semakin besar maka volume poripori yang terbentuk semakin banyak. Bila volume pori-pori semakin banyak berakibat pada penurunan nilai kuat tekan beton yang dalam hal ini adalah RPC.

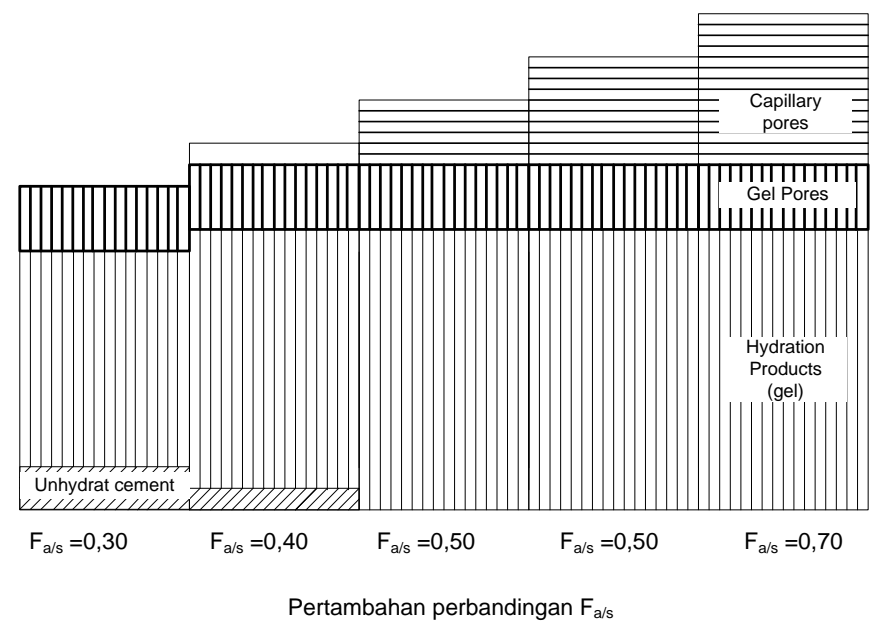

Gambar 2. Korelasi perbandiangan kadar air semen $\left(\mathrm{F}_{\mathrm{a} / \mathrm{s}}\right)$ dengan volume produk hidrasi (Mindess dan Young, 1981)

Keretakan yang muncul pada silinder beton identik dengan kekuatannya. Pada benda padat kekutan bergantung pada ikatan antar atom, sehingga bila membicarakan besarnya kekuatan tekan pada silinder maka yang di bicarakan adalah interaksi antar dua atom pada silinder tersebut. Setiap Atom mempunyai energi dasar $\left(\mathrm{U}_{0}\right)$ yang merupakan fungsi jarak antar atomnya $(\mathrm{b})$, untuk merubah jarak antar atom dari kondisi dasarnya $\left(b_{0}\right)$ ke jarak yang baru diperlukan sejumlah gaya $(F)$ yang digambarkan seperti ditunjukkan pada Gambar 3.3a. Gambar 3.3b. memperlihatkan gaya maksimum yang diperlukan untuk membuat jarak antar atom maksimum $\left(\mathrm{b}_{\mathrm{mak}}\right)$, artinya pada $\mathrm{F}$ maksimum mulai terbentuk keretakan yang pertama. 
Gambar 3.4. menggambarkan kurva tegangan regangan di tingkat atomik. Luasan di bawah kurva menggambarkan kerja yang harus dilakukan untuk menyebabkan terjadinya keretakan. Kekuatan ikatan secara teoritis antar atom dituliskan sebagai $\sigma_{\text {mak. }}$

$$
\sigma_{m a k}=\left(\frac{E \gamma_{s}}{b_{0}}\right)^{\frac{1}{2}}
$$

$\gamma_{\mathrm{s}}=$ Energi permukaan

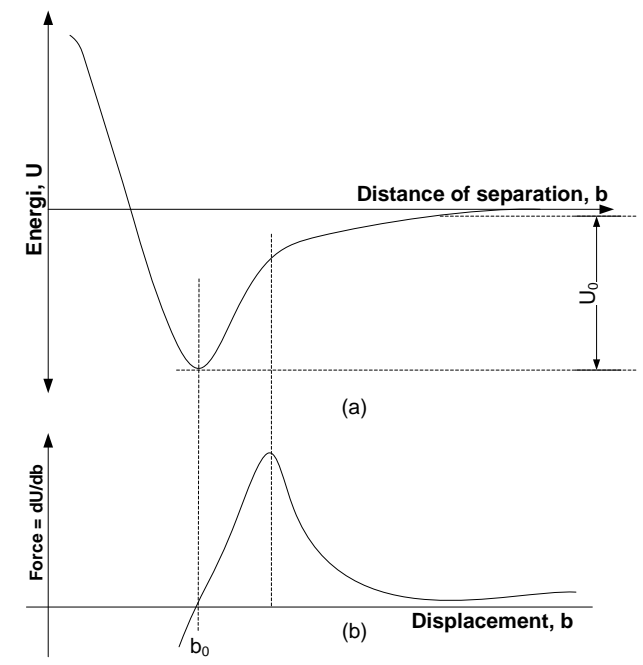

Gambar 3. a. Kurva energi ikat antar atom sebagai fungsi jarak antar atom. b. Kurva hubungan gaya terhadap pergeseran jarak antar atom (Mindes dan Young, 1981)

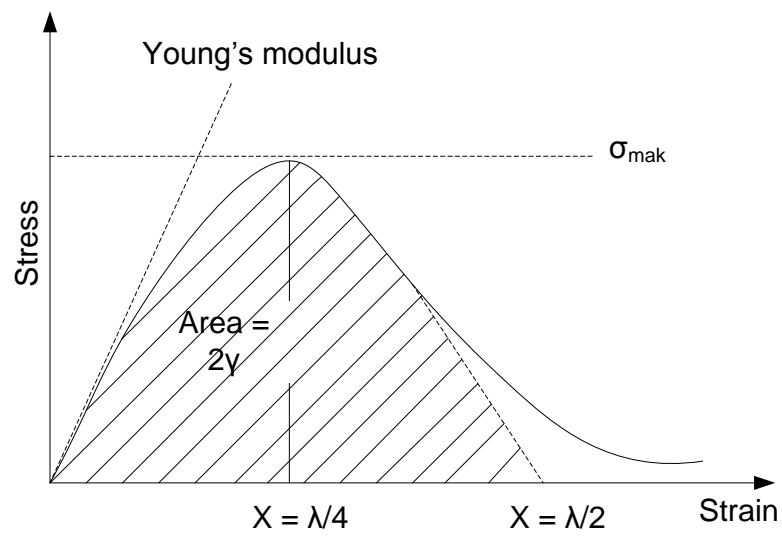

Gambar 4. Kurva tegangan-regangan tingkat atomik (Mindess dan Young, 1981) 
Untuk mengatasi gaya ikat antar atom diperlukan sejumlah energy (U). Energi merupakan hasilkali gaya (P) terhadap besarnya pergeseran atau displacement (b). Gaya yang bekerja pada silinder tiap satuan luas merupakan tegangan (persamaan-3).

\section{KESIMPULAN DAN SARAN}

\section{Kesimpulan}

Berdasarkan analisis yang telah dilakukan maka dapat diambil kesimpulan sebagai berikut:

a. Besar butiran maksimum agregat halus dan perbandingan faktor air semen pada perencanaan campuran reactive powder concerete mempengaruhi nilai kuat tekan recative powder concrete.

b. Semakin besar ukuran butiran maksimum agregat halus yang digunakan pada perencanaan campuran recative powder concrete, akan semakin menurunkan nilai kuat tekan recative powder concrete.

c. Pada perencanaan campuran recative powder concrete, apabila nilai perbandingan faktor air semen semakin besar maka akan berakibat semakin menurunnya nilai kuat tekan recative powder concrete.

d. Retak pertama yang muncul pada proses pembebanan balok recative powder concrete menyatakan nilai kuat tekan recative powder concrete.

e. Keretakan yang muncul saat pembebanan dilakukan, menandakan putusnya ikatan antar atom yang menopang kekuatan recative powder concrete.

\section{Saran}

Perlu dilakukan pemeriksan mikroskopis menggunakan scaning electron microscopy (SEM) untuk melihat kepadatan struktur mikro secara visual.

\section{Ucapan Terima Kasih}

Penulis mengucapkan terimakasih kepada Direktorat Penelitian dan Pengabdian Kepada Masyarakat Universitas Tarumangara (DPPM) yang telah membiayai penelitian ini.

\section{REFERENSI}

Ahmad, S. Zubair, A. Maslehuddin, M. (2015). Effect of key mixture parameters on flow and mechanical properties of reactive powder concrete, Construction and Building Materials, 99, 73-81.

Chang, Ping-Kun (2004). An approach to optimizing mix design for properties of highperformance concrete, Cement and Concrete Research, 34(4), 623-629

Graybeal, Benjamin A. (2007), Compressive Behavior of Ultra-High-Performance FiberReinforced Concrete, ACI Materials Journal, March- April.

Hiremath, Parameshwar N. and Yaragal, Subhash C. (2017). Effect of different curing regimes and durations on early strength development of reactive powder concrete, Construction and Building Materials 154, 72-87.

Hong-seok Jang, Hyoung-seok So, Seungyoung So (2016). The Properties Of Reactive Powder Concrete Using PP Fiber And Pozzolanic Materials At Elevated Temperature, Journal of Building Engineering, 8, 225-230.

Hou, X., Abid, M., Zheng, W., Waqar, Ghulam Q. (2017), Evaluation of residual mechanical properties of steel fiber-reinforced reactive powder concrete after exposure to high temperature using nondestructive testing, Procedia Engineering, 210, 588-596. 
JU, Yang, Liu, Jinhui, Liu, Hongbin, Tian, Kaipei, Ge, Zhishun (2016). On the thermal spalling mechanism of reactive powder concrete exposed to high temperature: Numerical and experimental studies, International Journal of Heat and Mass Transfer,98, 493-507

JU, Yang. Tian, Kaipei. Liu, Hongbin. Hans-Wolf Reinhardt. Wang, Li (2017). Experimental investigation of the effect of silica fume on the thermal spalling of reactive powder concrete, Construction and Building Materials, 155, 571-583

Kamen, Aicha,(2007),"Thermal Effects on Physico-Mechanical Properties of Ultra-HighPerformance Fiber-Reinforced Concrete, ACI Materials Jurnal,July-Agustus pp 414-423.

Khadiranaikar R.B.; S.M., Muranal (2012), Factor affecting the strength of reactive powder concrete $(R P C)$, International Journal Of Civil Engineering And Technology (Ijciet), vol 3, July - Dec, pp. $455-464$.

Mindess, Sidney and Young, J. Francis (1981). Concrete. Prentice-Hall, INC, New Jersey.

Neville, A.M. (2012). Properties of Concrete. Prentice-Hall, INC, New Jersey.

Phuoc, HUYNH Trong and Lung, HWANG Chao (2018). An Assessment of Characteristics of Densified High-Performance Concrete Incorporating High Volume Fly Ash, Material Science Forum, ISSN: 1662-9752, 923, 109-109.

Purwati, A., As'ad, S., Sunarmasto (2014). Pengaruh Ukuran Butiran Agregat Terhadap Kuat Tekan Dan Modulus Elastisitas Beton Kinerja Tinggi Grade 80, e-Jurnal Matriks Teknik Sipil, Vol. 2 No. 2, ISSN 2354-8630, 58-63. 
